\title{
Towards an Understanding of Physiological and Biochemical Mechanisms of Drought Tolerance in Plant
}

\author{
Yogendra K. Meena ${ }^{1^{*}}$ and Nirmaljit Kaur ${ }^{2}$ \\ ${ }^{1}$ Department of Vegetable Science, Punjab Agricultural University, Ludhiana, Punjab 141-004, India. \\ ${ }^{2}$ Department of Botany, Punjab Agricultural University, Ludhiana, Punjab 141-004, India.
}

Authors' contributions

This work was carried out in collaboration between both authors. Author YKM managed the literature searches and wrote the first draft of the manuscript. Author NK critically review the manuscript. Both authors read and approved the final manuscript.

Article Information

DOI: 10.9734/ARRB/2019/v31i230042

Editor(s):

(1) Dr. George Perry, Dean and Professor of Biology, University of Texas at San Antonio, USA.

Reviewers:

(1) Mueen Alam Khan, The Islamia University of Bahawalpur, Pakistan. (2) Martín Maria Silva Rossi, Estudio Agronómico, Santa Fé Argentina, Argentina. Complete Peer review History: http://www.sdiarticle3.com/review-history/37934

Review Article

Received 05 September 2017

Accepted 24 November 2017 Published 25 March 2019

\section{ABSTRACT}

Drought stress is one of the major abiotic stress that can causes huge loss to the world food production. It remains a major contributor to severe food shortage and famine. With a consistent increase in world population, pressure will continue to mount on the existing yet limited water resources. The situation is respected to further aggravate due to the predicted increase in temperature and decrease in precipitation consequent upon global warming. Water scarcity has already become a severe constraint in plant survival and productivity of crops in arid and semi-arid regions. The active response of plants to drought stress through various biochemical and physiological modifications improves the metabolism and can further the mobilize various defense mechanisms in order to enhance survival of the plants under conditions of drought. In this review, various physiological and biochemical responses in plants towards enhancement of drought tolerance are discussed. 
Keywords: Drought stress tolerance; plant; physiological and biochemical mechanisms.

\section{INTRODUCTION}

Drought is one of the most significant abiotic stress that limits the growth and productivity of crop plants [1]. Drought triggers a wide array of plant responses, ranging from cellular metabolism to changes in growth rates and crop yields. Exposure of plants to extreme stress conditions such as drought initiate a diverse set of physiological, morphological and developmental changes in order to survive in adverse condition, as has been widely reported $[2,3]$. However, tailoring crops in under to enable them to grow successfully in environments that are drought prone is promising [4]. Drought stress progressively decreases $\mathrm{CO}_{2}$ assimilation rates due to reduced stomatal conductance. It reduces leaf size, stem extension and root proliferation; disturbs plant water relations and reduces water-use efficiency. It disrupts the photosynthetic pigments and reduces the gas exchange leading to a reduction in plant growth and productivity. The critical role of osmolyte accumulation under drought stress conditions has been researched actively to understand the tolerance of plants to dehydration [4]. Several mechanisms have been adopted by drought tolerant plants to adapt to water stress including reduction in water loss by increasing stomatal resistance, increase of water uptake by developing large and deep root system and accumulation of osmolytes [5]. The accumulated osmolytes are amino acids such as proline, glutamate, glycine-betaine and sugars (mannitol, sorbitol and trehalose). These compounds play a key role in preventing membrane disintegration and enzyme inactivation in the low water available environment. Plants display a variety of physiological and biochemical responses at cellular and whole-organism level towards prevailing drought stress, thus making it a complex phenomenon. The identification of suitable plant characters for screening large number of genotypes in a short time at critical stage of crop growth with the aim of selecting drought tolerant cultivars remains a major challenge to the plant breeder $[4,6]$.

The measurement of solute leakage from plant tissue is a proven method for measuring membrane integrity in relation to environmental stress [7]. This technique involves measurement of electrolyte leakage into an aqueous medium, where the degree of cell membrane stability is considered to be one of the best physiological indicators of drought stress tolerance [8]. Maintenance of turgor pressure during stress is important to preserve metabolic response in crop species and is a well recognized mechanism in breeding toward drought stress tolerance. Relative water content (RWC) allows for the comparison of metabolic changes in the plant, at the same cellular water status. RWC further allows the estimation of plant water status in terms of cellular hydration and is under the possible effect of both leaf water potential and osmotic adjustment. RWC can be used effectively to evaluate drought tolerance and selection of the most drought tolerant genotypes [9]. Plants have evolved a number of enzyme and non-enzyme antioxidants that ameliorate oxidative stress by scavenging reactive oxygen species (ROS). Drought stress causes oxidative injury, and the ability to increase the levels of antioxidative capacity or increased levels of antioxidants during stress can limit membrane damage and enzyme activity can be an important measurement of drought tolerance There are numerous reports on these enzymes protecting plants during oxidative stress initiated by drought $[5,6,10,11]$.

Although plant stress tolerance mechanisms are not known clearly, accumulation of new proteins and stress gene expression that encode biosynthetic enzymes against osmotic stress have been investigated. Also a study on gene proteins have shown that osmotic proteins increase in low water stress [12]. The quantity of aquaporin existing in plasma membrane regulates membrane hydrolytic function and increases water permeability under environmental factors like low water, hormones and light conditions.

\section{PLANTS ARE CATEGORIZED BROADLY DEPENDING UPON THEIR RESPONSE TO DROUGHT}

\subsection{Drought Escape}

Drought escape is defined as the ability of a plant to complete its life cycle before serious soil and plant water deficits occurs. This mechanism involves rapid phenological development (early flowering and early maturity), developmental plasticity (variation in duration of growth period depending on the extent of water deficit) and remobilization of pre anthesis assimilates [13]. 


\subsection{Drought Avoidance}

Drought avoidance comprises of mechanisms that reduce water loss from plants, by stomatal control of transpiration, and also maintain water uptake through an extensive and prolific root system [14]. Hence, drought avoidance involves minimizing water loss (closing stomata, reducing light absorbance through rolled leaves, decreasing canopy leaf area) and maximizing water uptake (increasing investment in the root, reallocation of nutrients stored in older leaves, higher rates of photosynthesis) [15].

\subsection{Drought Tolerance}

Drought tolerance is the ability of plants to withstand water-deficit with low tissue water potential. The mechanism of drought tolerance is maintenance of turgor through osmotic adjustment (accumulation of solutes in the cell), increased cell elasticity \& decreased cell size and desiccation tolerance by protoplasmic resistance [13].

\section{PHYSIOLOGICAL AND BIOCHEMICAL RESPONSE}

Drought stress causes tissue dehydration which is characterized by fundamental changes in water relations, physiological and biochemical processes, membrane structure as well as ultrastructure of subcellular organelles. At the whole-plant level, drought stress leads to a progressive suppression of photosynthesis caused by stomatal and non-stomatal limitations. Tolerant genotypes not only retain sufficient water under drought, but also have a highly active system for protection against oxidative stress injury.

\subsection{Photosynthetic Pigments}

Photosynthetic pigments are important to plants mainly for harvesting light and production of reducing power [16]. Chlorophyll is one of the major chloroplast components for photosynthesis, and relative chlorophyll content has a positive relationship with photosynthetic rate. The decrease in chlorophyll content under drought stress has been considered a typical symptom of oxidative stress and may be the result of pigment photo-oxidation and chlorophyll degradation as reported in cherry tomato [17]. The Chlorophyll a and b ratio reduced in resistant species of tomato against low water condition and this indicated that photosystem II protects the plant against low water stress [18]. Drought stress is known to inhibit photosynthetic activity in tissues due to an imbalance between light capture and its utilization [4]. The decrease in the maximum quantum yield of PSII photochemistry FV/FM (Variable fluorescence: Maximum fluorescence) implies a decrease in the capture and conversion rate of excitation energy by PSII reaction centre and so, a reduction in PSII photochemical efficiency indicating the disorganisation of PS II reaction centres under water stress conditions. In general, the harvested energy in excess of that consumed by the Calvin Cycle must be dissipated to avoid oxidative stress which leads to decrease PSII performance. FV/FM was not affected by drought in Calluna, but a small (1.5\%) yet significant decrease was seen in Deschampsia across season. Photosystem II (PSII) is highly sensitive to light and down regulation of photosynthesis under drought stress causes an energy imbalance in the PSII reaction centre leading to photo-inhibition [19]. Mechanisms have evolved in the plant to protect from photoinhibition, such as non photochemical quenching, transport to molecules other than $\mathrm{CO}_{2}$, particularly to oxygen, which leads to photorespiration and Mehler reaction [20], nonradiative energy dissipation mechanisms [21] and chlorophyll concentration changes [19].

\subsection{Stomatal Conductance}

One of the basic mechanisms for reducing the impact of drought is early stomatal closure at the beginning of the period of water deficit. Stomatal closure not only reduce water loss, but also reduce the gas exchange between the plant and the ambient air. The reduced $\mathrm{CO}_{2}$ intake then results in reduced photosynthesis [22]. As plant water potential falls due to water deficit, photosynthesis rate reduces. Water deficit causes reduction in photosynthesis mainly due to decreased stomatal conductance. Stomatal closure has been reported in tomato at leaf water potential (leaf) between -0.7 to $0.9 \mathrm{MPa}$ [23], in pepper at -0.58 to $-0.88 \mathrm{MPa}$ [24], however eggplant can withstand a greater drought than the most other vegetables. Bahadur et al. [25] observed significant reduction in photosynthesis rate and stomatal conductance in spring-summer okra when water stress was imposed for 10 or 12 days. Although stomatal conductance is the major limitation to photosynthesis under drought conditions in cowpea; however, a pronounced non-stomatal limitation may occur under severe drought stressed conditions that may also lead to 
impairment of photosynthetic activity [26]. If perpetual decline in photosynthesis is more than the transpiration, then non-stomatal factors contribute more to the reduction of photosynthesis than the stomatal effects. This is because stomatal resistance accounts for a smaller portion of total resistance in $\mathrm{CO}_{2}$ pathway. During this non-stomatal control of photosynthesis, intercellular resistance for $\mathrm{CO}_{2}$ from the intercellular space of the chloroplasts plays an important role. Thus, a decrease of the photosynthetic rate under water deficit condition can be attributed to both stomatal and nonstomatal limitations. Non-stomatal photosynthesis limitation has been attributed to the reduced carboxylation efficiency, ribulose-1,5bisphospate (RuBP) regeneration, amount of functional Rubisco, or to the inhibited functional activity of PSII. The drought-tolerant species control stomatal function to allow some carbon fixation during stress, thus improving water use efficiency, or open stomata rapidly when water deficit is relieved. In fact, stomatal conductance can be used as an integrative parameter to reflect the severity of drought stress.

\subsection{Cell Membrane Stability}

A major impact of plant environmental stress is cellular membrane modification, which results in its perturbed function or total dysfunction. The cellular membrane dysfunction due to stress is expressed by increased permeability and leakage of ions, which can be readily measured by the efflux of electrolytes, and may be used as a tolerance index for drought stress [27]. It is generally accepted that the maintenance of integrity and stability of membranes under water stress is a major component of drought tolerance in plants [28]. Cell membrane stability declined rapidly in Kentucky bluegrass when exposed to drought. Cell membrane stability, reciprocal to cell membrane injury is a physiological index widely used for the evaluation of drought tolerance. Moreover, it is a genetically related phenomenon since quantitative trait loci for this have been mapped in drought-stressed rice at different growth stages. Dhanda et al. [29] showed that membrane stability of the leaf segment was the most important trait to screen the germplasm for drought tolerance. The increase in cell membrane stability under water deficit conditions in response to drought stress is species specific and correlation with a reduction in relative growth rate. In holm oak (Quercus ilex) seedlings, hardening increased drought tolerance primarily by reducing osmotic potential and stomatal regulation, improved new root growth capacity and enhanced cell membrane stability. Among treated seedlings, the greatest response occurred in seedlings subjected to moderate hardening. Variation in cell membrane stability, stomatal regulation and root growth capacity was negatively related to osmotic adjustment [30].

\subsection{Relative Water Content}

Relative water content (RWC) is related to water uptake by the roots as well as water loss by transpiration. A decrease in the RWC in response to drought stress has been noted in wide variety of plants as reported by Nayyar and Gupta [31] that leaves when subjected to drought, exhibit large reductions in RWC and water potential. Exposure of plants to drought stress substantially decrease the leaf water potential, relative water content and transpiration rate with a concomitant increase in leaf temperature. RWC is affected by the interaction of severity, duration of the drought and species $[4,32]$. Bahadur et al. [33] noticed significant reduction in leaf RWC in okra and tomato with imposing drought tolerance. When RWC can be maintained in cells and tissues, it allows continuation of the metabolic activity by osmotic adjustment and other traits of adaptation to drought. Recovery of RWC after re-watering is a very important factor and often neglected in drought tolerant studies [5]. In faba bean, determination of leaf water potential was useful for describing the drought effect, but was not suitable for discriminating tolerant from sensitive genotypes. This suggested that water potential was not the defining feature of the tolerance [34]. Nevertheless, other studies opined that determination of leaf water status in the morning and water content in leaves in the afternoon were potentially useful for screening drought tolerance in chickpea [35]. The RWC correlated indirectly with the activity of SOD, GR and APX, arein $A$. hypochondriacus decreased to a very low $33 \%$ after 17 days of severe drought stress [5]. Similarly a sharp decline in RWC below $30 \%$ was experienced several Bermuda grass spp [36], below $40 \%$ in spruce sp. and $45 \%$ in maize [37] during severe drought stress.

\subsection{Water Use Efficiency}

Water use efficiency is an important indicator for plant adaptation and resistance to drought conditions [38]. Water use efficiency (WUE) is traditionally defined either as the ratio of dry 
matter accumulation to water consumption over a season; or as the ratio of photosynthesis to transpiration over a period of time. It is among one of traits that has been studied extensively because it can give an idea of the variation amongst genotypes in their ability to utilize water efficiently under limited water supply [39]. Comprehensive literature on crop WUE based on carbon isotope dissemination studies depicts relation of WUE and drought tolerance with yield potential. Briefly, apparent genotypic variations in WUE are expressed mainly due to variations in water use. Higher WUE is generally achieved by specific plant traits and environmental responses that reduce yield potential in tomato [40]. Under most dryland situations where crops rely on unpredictable seasonal rainfall, the maximization of soil moisture use is a crucial component of drought resistance (avoidance), which is generally expressed in lower WUE [41]. It is now well documented that high yield potential and high yield under water-limited conditions is generally associated with reduced WUE mainly because of high water use [25].

\subsection{Osmotic Adjustment}

Osmotic adjustment (OA) has been considered as an important physiological adaptation associated with drought tolerance and has drawn substantial attention during the past years. Osmotic adjustment is defined as the active accumulation of organic solutes in the plant tissue in response to an increasing water deficit. By means of osmotic adjustment, the organelles and cytoplasmic activities take place at about a normal pace and help plants to perform better in terms of growth, photosynthesis and assimilate partitioning $[4,16]$. It is considered as a useful process for maintaining cell turgor when tissue water potential declines. OA has been shown to maintain stomatal conductance and photosynthesis at lower water potentials, delayed leaf senescence and death, reduced flower abortion, improved root growth and increased water extraction from the soil as water deficit develops [42]. OA involves the net accumulation of solutes in a cell in response to fall in water potential of the cell's environment. As a consequence, the cell's osmotic potential is diminished which in turn attracts water into the cell by tending to maintain turgor pressure. According to Martinez-Ballesta et al. [43] compatible solutes like sugars, glycerol, amino acids such as proline or glycinebetaine, polyols, sugar alcohols (like mannitol and other low molecular weight metabolites) would also contribute to this process. In addition, Hessini et al. [44] argued that these compounds benefit stressed cells in two ways: either by acting as cytoplasmic osmolytes, thereby facilitating water uptake and retention and or by protecting and stabilizing macromolecules and structures (i.e. proteins, membranes, chloroplasts, and liposomes) from damage induced by stress conditions. Physiological indices such as leaf water potential, solute potential, relative water content, turgor potential, osmotic adjustment, leaf diffusive conductance $(\mathrm{KI})$, difference between canopy and air temperature and water loss from excised leaves can be used as a screening tools. Improved tissue water status may be achieved through osmotic adjustment and/or changes in cell wall elasticity. This is essential for maintaining physiological activity for extended periods of drought [45]. Wild melon plant survived drought by maintaining its water content without wilting of leaves even under severe drought. Drought stress in combination with strong light led to an accumulation of high concentrations of citrulline, glutamate and arginine in leaves of wild watermelon. The accumulation of citrulline and arginine may be related to the induction of dopamine receptor interacting protein gene- 1 , a homologue of the acetyl ornithine deacetylase gene in Escherichia coli, where it functions to incorporate the carbon skeleton of glutamate into the urea cycle [46]. It has identified that among various mechanisms, osmotic adjustment, synthesis abscisic acid and induction of dehydrins may confer tolerance against drought injuries by maintaining high tissue water potential. The osmotic adjustment also facilitates a better translocation of preanthesis carbohydrate partitioning during grain filling, while high turgor maintenance leads to higher photosynthetic rate and growth [47].

\subsection{Proline}

Proline is generally considered as a good indicator of environmental stress and there are many reports describing an increase in proline content in response to water stress $[17,18]$. Ghorbanli et al. [18] suggested that Proline is one of the protective molecules that can unite oxygen and free radicals caused by stress. Therefore, a significant role of proline is probably reacting against drought stress [48]. Since proline plays a role as an osmotic factor, low water stress increased the proline content in plant. A relatively recent study on tomato found that use of brasinoestroid in two stress levels (mild and severe) increased the amount of 
proline ( 3 and 4 respectively) in comparison with control. The effect of drought stress was also investigated on ABA (abcisic acid) and proline in different Zea mays species and a close correlation was established between proline accumulation and ABA with drought stress [49].

According to Abdalla and El-Khoshiban [9] free proline may be acting as a storage compound for carbon and nitrogen during drought stress when both starch and protein synthesis are inhibited. Such a storage compound might be utilized for growth upon rewatering, and after rewatering the enhanced level of proline decreases rapidly [50]. It is possible that both proline accumulation and antioxidative enzyme activities could be used as an index of drought tolerance $[5,10]$. The higher proline accumulation accompanied by higher enzyme activities of SOD, APX and CAT could suggest that the antioxidative defense mechanism is activated by increased proline production $[5,10]$. Proline acts as an osmolite beside enzymes and other macromolecules, and therefore, protects the plant against low water potential and causes osmotic regulation in plant organs [18,48]. Also proline can act as an electron receptor preventing photosystem injuries in dealing with ROS function. Proline accumulation facilitates the permanent synthesis of soluble substances in closing stomata.

\subsection{Soluble Sugars}

The accumulation of soluble sugars (sucrose, glucose and fructose) is strongly correlated to the acquisition of drought tolerance in plants [51]. It is well known that sugars protect the cells during drought by two mechanisms. First, the hydroxyl groups of sugars may substitute for water to maintain hydrophilic interactions in membranes and proteins during dehydration. Hence, sugars interact with proteins and membranes through hydrogen-bonding, thus preventing protein denaturation. Secondly, sugars are a major contributing factor to vitrification, which is the formation of a biological glass in the cytoplasm of dehydrated cells. These intracellular glasses, by virtue of their high viscosity, drastically reduce molecular movement, impede the diffusion of reactive compounds in the cell, and may maintain the structural and functional integrity of macromolecules. It is by this property that glasses are thought to prolong the longevity of desiccated tissues by slowing down degradation processes during storage [17]. Mutava et al. [52] reported that fructose accounted for much of the significant increase in leaf total sugars under drought stress. Some studies have pointed out that soluble sugar changes do not follow a static model and may vary with the genotype and the stress factor [53]. Gupta and Kaur [54] suggested that sucrose and glucose either act as substrates for cellular respiration or osmolytes to maintain cell homeostasis while fructose is involved in the synthesis of secondary metabolites as well as erythrose-4-P, which act's as a substrate in lignin and phenolic compound synthesis [55]. This suggests that under stress conditions the metabolism of soluble sugars is a dynamic proces involving simultaneously degradation and synthetic reactions $[17,52]$. Soluble sugars, especially sucrose, accumulate in seeds, pollen and in drought-tolerant vegetative tissues. In many higher plants under dehydration stress, carbohydrate metabolism is shifted to favour the conversion of other sugars to sucrose. Trehalose, a non-reducing sugar, is also a potential organic osmoticum which has a substantial role in the protection of plants against drought stresses [56].

\subsection{Reactive Oxygen Species (ROS)}

ROS are partially reduced forms of atmospheric oxygen. They typically result from the excitation of $\mathrm{O}_{2}$ to form singlet oxygen $\left(\mathrm{O}_{2}{ }^{1}\right)$ or from the transfer of 1,2 or 3 electrons to $\mathrm{O}_{2}$, for superoxide radical, hydrogen peroxide $\mathrm{H}_{2} \mathrm{O}_{2}$ or a hydroxyl radical $\left(\mathrm{OH}^{\circ}\right)$, respectively. The cells are normally protected against ROS by the operation of the antioxidant defense system comprising enzymatic and non-enzymic components. The activities of enzymes of the antioxidant system in plants under stress are usually regarded as an indicator of the tolerance of genotypes against stress conditions. Overall, the involvement of ROS in various metabolic processes in plant cells might have general implications. Drought stress enhances the production of ROS in cellular compartments such as chloroplasts, peroxisome and mitochondria. ROS causes the peroxidation of membrane lipids, the denaturation of proteins and damage to nucleic acids [57]. If drought stress is prolonged, ROS productions will un-date the scavenging action of the antioxidant system, resulting in extensive cellular damage and eventual death. ROS are highly deleterious byproducts of stress, and are likely to be important secondary messengers that trigger adaptation responses to the changing environment [58]. Drought stress induces the formation of active oxygen species by misdirection of electrons in the true photosystem. 


\subsection{Antioxidant}

The antioxidant defense system in the plant cell constitutes both enzymatic and non-enzymatic components. Non-enzymatic components include $\beta$-carotene, ascorbate (ASC), $\alpha$-tocopherol, reduced glutathione (GSH), carotenoid, enzymes include superoxide dismutase (SOD), peroxidase (POD), ascorbate peroxid (APX), catalase (CAT), polyphenol oxidase (PPO) and glutathione reductase (GR) [59]. In environmental stress tolerance, such as drought, high activities of antioxidant enzymes and high content of nonenzymatic constituents are important. The reactive oxygen species in plants are removed by a variety of antioxidant enzymes and lipidsoluble and water soluble scavenging molecules, the antioxidant enzymes being the most efficient mechanism against oxidative stress [35]. Apart from catalase, various peroxidases and peroxiredoxins, four enzymes are involved in the ascorbate-glutathione cycle, a pathway that allows the scavenging of superoxide radicals and $\mathrm{H}_{2} \mathrm{O}_{2}$. These include ascorbate peroxidase, dehydroascorbate reductase (DHAC), monodehydroascorbate reductase and glutathione reductase [60]. The ascorbate glutathione cycle enzymes are located in the cytosol, stroma of chloroplasts, mitochondria and peroxisomes. Ascorbate peroxidase is the key antioxidant enzyme in plants whilst glutathione reductase has a central role in maintaining the reduced glutathione pool during stress [61]. Two glutathione reductase complementary deoxyribonucleic acids have been isolated; type one encoding the cytosolic isoforms [62] and the other encoding glutathione reductase proteins dual-targeted to both chloroplasts and mitochondria in different plants [63]. The capability of antioxidant enzymes to scavenge ROS and reduce the damaging effects may correlate with the drought resistance of plants [4]. The transcript of some of the antioxidant genes such as glutathione reductase or ascorbate peroxidase was higher during recovery from a water deficit period and appeared to play a role in the protection of cellular machinery against damage by reactive oxygen species [16].

\subsection{Carotenoids}

Carotenoids a tetra-terpenoids are pigments with several functions in plants, besides their direct role in photosynthesis, they are actively involved in the mechanisms of oxidative stress tolerance. Carotenoids are a large class of isoprenoid molecules, which are synthesized by all photosynthetic and many non-photosynthetic organisms. They are divided into the hydrocarbon carotenes, such as lycopene, $\alpha$ carotene and $\beta$-carotene, and xanthophylls, typified by lutein. Carotenes form a key part of the plant antioxidant defense system, but they are very susceptible to oxidative destruction. $\beta$ carotene, present in the chloroplasts of all green plants is exclusively bound to the core complexes of PSI and PSII. Protection against damaging effects of ROS at this site is essential for chloroplast functioning. In addition to the function at an accessory pigment, $\beta$-carotene acts as an effective antioxidant and plays a unique role in protecting photochemical processes and sustaining them. A major protective role of $\beta$-carotene in photosynthetic tissue may be through direct quenching of triplet chlorophyll, which prevents the generation of singlet oxygen and protects from oxidative damage [16]. Unyayar et al. [64] observed decreased chlorophyll $a / b$ ratio in drought tolerant Lycopersicon peruvianum and concluded that this trait indicates better protection of PSII against drought stress. An increase in carotenoid/chlorophyll ratio might be of a protective value as carotenoids are known to be potent quenchers of ROS, particularly singlet oxygen. Carotenoids and other compounds, such as abietane diterpene, have received little attention despite their capacity to scavenge singlet oxygen and lipid peroxy-radicals, as well as to inhibit lipid peroxidation and superoxide generation under dehydrative forces [65].

\subsection{Tocopherols}

Tocopherol, a lipid soluble antioxidant is considered as a potential scavenger of ROS and lipid radicals [66]. Tocopherols are considered as major antioxidant in biomembranes, where they play both antioxidant and non-antioxidant functions. Tocopherols are considered general antioxidants for protection of membrane stability, including quenching or scavenging ROS [67]. They are localized in plants in the thylakoid membrane of chloroplasts. Out of four isomers of tocopherols found in plants, $\alpha$-tocopherol has the highest antioxidative activity due to the presence of three methyl groups in its molecular structure. Increased levels of $\alpha$-tocopherol and $\mathrm{ASH}$ have been found in tomato following trizole treatment which may help in protecting membranes from oxidative damage [68].

\subsection{Glutathione (GSH)}

Glutathione (GSH, g-glutamyl-cysteinyl-glycine) is a low molecular weight thiol-metabolite and a 
major antioxidant in plant cells. Glutathione is present in most eukaryotic organisms, where it performs multiple functions. These include storage and transport of sulphur and control of the redox status. $\mathrm{GSH}$ is a strong reductant that can scavenge ROS directly or in cooperation with other antioxidants and ROS processing enzymes. It seems likely that GSH levels are used as a cue in the coordination of mechanisms for the supply of cysteine and the maintenance of the cellular NADPH pool. Coordination of these responses, merely by lowering the GSH pool, provides plants with a simple mechanism to respond defensively to a wide range of stresses through a coordinated up-regulation of the capacity for GSH biosynthesis and its redox cycling [5].

\subsection{Catalase}

Plant catalases are tetrameric iron porphyrins and play a role in stress tolerance against oxidative stress. Catalases are produced in peroxisomes and glyoxysomes. These are involved in eliminating hydrogen peroxide generated by different environmental stresses $[69,70]$. Catalase decomposes hydrogen peroxide to water and molecular oxygen without consuming reductants and thus may provide plant cells with an energy efficient mechanism to remove hydrogen peroxide [70]. The enzyme is abundant in the glyoxysomes of lipid-storing tissues in germinating barley, where it decomposes $\mathrm{H}_{2} \mathrm{O}_{2}$ formed during the oxidation of fatty acids and in the peroxisomes of the leaves of $\mathrm{C}_{3}$ plants, where it removes $\mathrm{H}_{2} \mathrm{O}_{2}$ generated during photorespiration by the conversion of glycolate into glyoxylate. This is also due to the fact that there is a proliferation of peroxisomes during stress, which might help in scavenging $\mathrm{H}_{2} \mathrm{O}_{2}$ [71].

\subsection{Glutathione Reductases (GR)}

GR is a flavo-protein oxidoreductase, found in both prokaryotes and eukaryotes [72]. It is a potential enzyme of the ASH-GSH cycle and plays an essential role in defense system against ROS by sustaining the reduced status of GSH. It is localized predominantly in chloroplasts, but small amount of this enzyme has also been found in mitochondria and cytosol. GR catalyzes the reduction of glutathione (GSH), a molecule involved in many metabolic regulatory and antioxidative processes in plants, e.g., GR catalyses the NADPH dependent reaction of disulphide bond of oxidized glutathione (GSSG) and is thus, important for maintaining the GSH pool [73]. Actually, GSSG consists of two GSH molecules linked by a disulphide bridge which can be converted back to GSH by GR. GR is involved in defense against oxidative stress, whereas, GSH plays an important role within the cell system including participation in the $\mathrm{ASH}$ GSH cycle, maintenance of the sulfhydryl (eSH) group and a substrate for glutathione transferases (GSTs) [74]. It was suggested that GR plays an important role in the regeneration of GSH and thus protects against oxidative stress by maintaining the ASH pool [75].

\subsection{Malondialdehyde (MDA)}

Accumulation of MDA, mainly produced from the ROS induced degradation of membrane lipids, is a potential biomarker to assess the severity of the abiotic stress, including drought stress [76]. Membrane damage is sometimes taken as a single parameter to determine the level of lipid destruction under various stresses. Now, it has been recognized that during lipid peroxidation products are formed from polyunsaturated precursors that include small hydrocarbon fragments such as ketones, MDA, etc and their related compounds [77]. MDA is synthesized due to degradation of polyunsaturated lipids by ROS. The production of this aldehyde is used as a biomarker to measure the level of oxidative stress. Increased MDA accumulation has been correlated with reduction of relative water content and photosynthetic pigment content under prolonged drought. Lower MDA displays higher anti-oxidative ability, reflecting higher resistance to drought. These secondary metabolites play multiple roles in plants, including scavenging of ROS induced under different stress conditions and causing oxidative stress [78,79]. A clear symptom of oxidative damage is cell membrane degradation; therefore, MDA - a product of membrane lipid peroxidation is an excellent marker of oxidative stress [77]. A significant increase of MDA level in tomato leaves upon induced drought stress was observed [17].

\section{CONCLUSION}

As climate prediction models predict increased manifestation of drought, salinity, high and low temperature spells during the crop growth periods, global food production will continue to be challenged. Ensured sustainable yields under changing environmental conditions will therefore be imperative. Prolonged soil water deficit causing drought, is one of the prevalent abiotic 
stresses vastly responsible for the production of ROS in different cellular compartments like chloroplasts, mitochondria, peroxisomes, etc. which further attack biomolecules, viz., DNA, lipids, proteins, carbohydrates, thereby disturb the normal functioning of the cell. Different physiological mechanisms including stomatal conductance, osmatic adjustment, , water use efficiency, cell membrane stability and relative water content make it possible for the plant to tolerate the damage caused by drought stress. In order to withstand oxidative stress, plants are equipped with enzymatic and nonenzymatic antioxidants. Non-enzymatic (ascorbate, carotenoids and tocopherols) and enzymatic antioxidants (Catalase, glutathione, gluthione reductase, SOD, APX, etc.) have a predominantrole in combating oxidative damage of the cell. To overcome the deleterious effects of abiotic stress, plants accumulate osmolytes and osmoprotectants, particularly proline and glycine betaine. These compounds are thought to play a significant role in osmotic adjustment and protectection of subcellular structures thereby enhancing drought tolerance of plants. Manipulation of traits conferring drought tolerance can be exploited for sustaining qualitative and quantitative production in the conditiond of water scarcity.

\section{COMPETING INTERESTS}

Authors have declared that no competing interests exist.

\section{REFERENCES}

1. Petrozza A, Santaniello A, Summerer S, Di Tommaso G, Di Tommaso D, Paparelli E, et al. Physiological responses to Megafol treatments in tomato plants under drought stress: A phenomic and molecular approach. Sci. Hortic. 2014;174:185-192.

2. Gomes $P$, Oliva MA, Mielke MS, Almeida AAF, Aquino LA. Osmotic adjustment, proline accumulation and cell membrane stability in leaves of Cocos nucifera submitted to drought stress. Scientia Horti. 2010;126:379-384.

3. Kumar M. Crop plants and abiotic stresses. J Biomol Res Ther. 2013;3:1. Available:http://dx.doi.org/10.4172/21677956.1000e125

4. Anjum SA, Xiao-yu Xie, Wang L, Saleem MF, Chen M, Wang L. Morphological, physiological and biochemical responses of plants to drought stress. Afr J Agri Res. 2011;6(9):2026-2032.

5. Slabberta MM, Krüger GHJ. Antioxidant enzyme activity, proline accumulation, leaf area and cell membrane stability in water stressed Amaranthus leaves. S Afr J Bot. 2014;95:123-128.

6. Dawood MG, Taie HAA, Nassar MRA, Abdelhamid MT, Schmidhalter $U$. The changes induced in the physiological, biochemical and anatomical characteristics of Vicia faba by the exogenous application of proline under seawater stress. S Afr J Bot. 2014;93:54-63.

7. Farooq S, Azam F. The use of cell membrane stability (CMS) technique to screen for salt tolerant wheat varieties. J Plant Physiol. 2006;163:629-637.

8. Labuschagne MT, Verhoeven $R$, Nkouanessi M. Drought tolerance assessment of African cowpea accessions based on stomatal behaviour and cellmembrane stability. J Agri Scie. 2008; 146:689-694.

9. Abdalla MM, El-Khoshiban NH. The influence of water stress on growth, relative water content, photosynthetic pigments, some metabolic and hormonal contents of two Triticium aestivum cultivars. J Appl Scient Res. 2007;3:20622074.

10. Ahmed CB, Rouina BB, Sensoy $S$, Boukhris M, Abdallah FB. Changes in gas exchange, proline accumulation and antioxidative enzyme activities in three olive cultivars under contrasting water availability regimes. Environ Exp Bot. 2009;67:345-352.

11. Boogar AR, Salehi $H$, Jowkar $A$. Exogenous nitric oxide alleviates oxidative damage in turfgrass under drougt stress. S Afr J Bot. 2014;92:78-82.

12. Hajheidari $M$, Abdollahian-Noghabi $M$, Askari $\mathrm{H}$. Proteome analysis of sugar beet leaves under draught stress. Proteomics. 2005;5:463-99.

13. Agbicodo EM, Fatokun CA, Muranaka S, Visser RGF, Linden van der CG. Breeding drought tolerant cowpea: Constraints, accomplishments, and future prospects. Euphytica. 2009;167:353-370.

14. Kavar T, Maras M, Kidric M, Sustar-Vozlic $\mathrm{J}$, Meglic V. Identification of genes involved in the response of leaves of Phaseolus vulgaris to drought stress. Mol Breed. 2007;21:159-172. 
15. Chaves MM, Maroco JP, Pereira JS. Understanding plant responses to drought from genes to the whole plant. Funct Plant Biol. 2003;30:239-264.

16. Farooq M, Wahid A, Kobayashi N, Fujita D, Basra SMA. Plant drought stress: Effects, mechanisms and management. Agron Sustain Dev. 2009;29:185-212.

17. Hassan MAL, Fuertes MM, Sanchez FJR, Vicente O, Boscaiu M. Effects of salt and water stress on plant growth and on accumulation of osmolytes and antioxidant compounds in cherry tomato. Not Bot Horti Agrobo. 2015;43(1).

DOI: $10.15835 /$ nbha4319793

18. Ghorbanli M, Gafarabad M, Amirkian T, Mamaghani BA. Investigation on proline, total protein, chlorophyll ascorbate and dehydroascorbate changes under drought stress in Akria and Mobil tomato cultivars. Iran J Plant Physiol. 2013;3(2):651-658.

19. Pastenes C, Pimentel P, Lillo J. Leaf movements and photoinhibition in relation to water stress in yield-grown beans. J Exp Bot. 2005;56:425-433.

20. Flexas J, Bota J, Escalona JM. Effects of drought on photosynthesis in grapevines under field conditions: An evaluation of stomatal and mesophyll limitations. Funct Plant Biol. 2002;29:461-471.

21. Souza RP, Machado EC, Silva JAB, Lagôa AMMA, Silveira JAG. Photosynthetic gas exchange, chlorophyll fluorescence and some associated metabolic changes in cowpea (Vigna unguiculata) during water stress and recovery. Environ Exp Bot. 2004;51:45-56.

22. Chaves MM, Oliveira MM. Mechanisms underlying plant resilience to water deficits: Prospects for water-saving agriculture. J Exp Bot. 2004;55:2365-2384.

23. Duniway JM. Water relation of Fusarium wilt of tomato. Physiol Plant. 1971;15:1021.

24. Srinivasa Rao NK, Bhatt RM. Photosynthesis, transpiration, stomatal diffusive resistance, and relative water content of Capsicum annum L. Grossum (bell pepper) grown under water stress. Photosynthetica. 1988;22:377-382.

25. Bahadur A, Chatterjee A, Kumar R, Singh $M$, Naik PS. Physiological and biochemical basis of drought tolerance in vegetables. Veg Sci. 2011;38(1):1-16.

26. Singh S, Reddy K Raja. Regulation of photosynthesis, fluorescence, stomatal conductance and water-use efficiency of cowpea (Vigna unguiculata [L.] Walp.) under drought. J Photochem Photobio B Bio. 2011;105:40-50.

27. Yang $Y$, Han C, Liu Q, Lin B, Wang J. Effect of drought and low light on growth and enzymatic antioxidant system of Picea asperata seedlings. Acta Physiol Plant. 2008;30:433-440.

28. Bajji M, Kinet J, Lutts $\mathrm{S}$. The use of the electrolyte leakage method for assessing cell membrane stability as a water stress tolerance test in durum wheat. Plant Growth Regul. 2001;36:61-70.

29. Dhanda SS, Sethi GS, Behl RK. Indices of drought tolerance in wheat genotypes at early stages of plant growth. J Agron Crop Sci. 2004;190:6-12.

30. Villar-Salvador $P$, Planelles $R$, Oliet $J$, Penuelas-Rubira JL, Jacobs DF, Gonzalez M. Drought tolerance and transplanting performance of holm oak (Quercus ilex) seedlings after drought hardening in the nursery. Tree Physiol. 2004;24:11471155.

31. Nayyar H, Gupta D. Differential sensitivity of C3 and C4 plants to water deficit stress: Association with oxidative stress and antioxidants. Environ Exp Bot. 2006;58: 106-113.

32. Yang F, Miao LF. Adaptive responses to progressive drought stress in two poplar species originating from different altitudes. Silva Fennica. 2010.44:23-37.

33. Bahadur A, Kumar R, Mishra U, Rai A, Singh M. Physiological approaches for screening of tomato genotypes for moisture stress tolerance. National Conference of Plant Physiology (NCPP2010) BHU, Varanasi During. 2010;142.

34. Riccardi L, Polignano GB, de Giovanni C. Genotypic response of faba bean to water stress. Euphytica. 2001;118:39-46.

35. Farooq M, Aziz T, Basra SMA, Cheema MA, Rehamn $\mathrm{H}$. Chilling tolerance in hybrid maize induced by seed priming with salicylic acid. J Agron Crop Sci. 2008;194: 161-168.

36. Hu L, Wang Z, Du H, Huang B. Differential accumulation of dehydrins in response to water stress for hybrid and common Bermuda grass genotypes differing in drought tolerance. J Plant Physiol. 2010; 167:103-109.

37. Efeoghu B, Ekmeçi Y, Çiçek N. Physiological response of three maize cultivars to drought stress and recovery. S Afr J Bot. 2009;75:34-42. 
38. Zhoua S, Lia M, Guana $Q$, Liua $F$, Zhangb S, Chenb WQ, Yina L, Qina Y, Ma F. Physiological and proteome analysis suggest critical roles for thephotosynthetic system for high water use efficiency under droughtstress in Malus Plant Science; 2015.

Available:http://dx.doi.org/10.1016/j.plantsc i.2015.03.0170

39. Galmes J, Conesa MÀ, J Ochogavía, JA Perdomo, DM Francis, M Ribas-Carbo, R Save, J Flexas, $H$ Medrano, Cifre J. Physiological and morphological adaptations in relation to water use efficiency in mediterranean accessions of Solanum lycopersicum. Plant Cell Environ. 2011;34: 245-260.

40. Chen S, Zhen-jiang Zhoub, Andersenb MN, Tian-tian Hua. Tomato yield and water use efficiency - coupling effects between growth stage specific soil water deficits. Acta Agric Scandinavica, Section B Soil Plant Scie. 2015;65(5):460-469.

41. Bassett BCL. Water use and drought response in cultivated and wild apples. In: Vahdati K, Leslie C (Eds.). Agricultural and Biological Sciences, Alpha Science International Ltd. UK. 2013;249-275.

42. Taiz L, Zeiger E. Plant Physiology, $4^{\text {th }}$ Ed., Sinauer Associates Inc. Publishers, Massachusetts; 2006.

43. Martinez-Ballesta MC, Martinez V, Carvajal M. Osmotic adjustment, water relations and gas exchange in pepper plants grown under $\mathrm{NaCl}$ or $\mathrm{KCl}$. Environ Exp Bot. 2004; 52:161-174

44. Hessini K, Martínez JP, Gandour M, Albouchi A, Soltani A, Abdelly C. Effect of water stress on growth, osmotic adjustment, cell wall elasticity and wateruse efficiency in Spartina alterniflora. Environ Exp Bot. 2009;67:312-319.

45. Kramer PJ, Boyer JS. Water relations of Plants and Soils Academic Press, San Diego; 1995.

46. Yokota A, Kawasaki S, Iwano M, Nakamura C, Miyake C, Akashi K. Citrulline and DRIP-1 protein (ArgE Homologue) in drought tolerance of wild watermelon. Ann Bot. 2002;89:825-832.

47. Subbarao GV, Nam NH, Chauhan YS, Johansen C. Osmotic adjustment, water relations and carbohydrate remobilization in pigeonpea under water deficits. J Plant Physiol. 2000;157:651-659.

48. Behnamnia M, Kh M Kalantari, Rezanejad F. Exogenous application of brassin- osteroid alleviates drought-Induced oxidative stress In Lycopersicon esculentum L. Gen Appl Plant Physiol. 2009;35:22-34.

49. Heidari Y, Moaveni P. Study of drought stress on ABA accumulation and proline among in different genotypes forage corn. Res J Biol Sci. 2009;4(10):1121-1124.

50. Hare PD, Cress WA, Van Staden J. Dissecting the roles of Osmolyte accumulation during stress. Plant Cell Environ. 1998;21:535-553.

51. Sgherri C, Kadlecová Z, Pardossi A, Navari-Izzo F, Izzo R. Irrigation with diluted seawater improves the nutritional value of cherry tomatoes. J Agri Food Chem. 2008; 56:3391-3397.

52. Mutava RN, Prince SJK, Syed NH, Song Li, Valliyodan B, Chen W, Nguyen HT. Understanding abiotic stress tolerance mechanisms in soybean: A comparative evaluation of soybean response to drought and flooding stress. Plant Physiol Biochem. 2015;86:109-120.

53. Morsy MR, Jouve L, Hausman JF, Hoffmann L, Stewart JD. Alteration of oxidative and carbohydrate metabolism under abiotic stress in two rice (Oryza sativa L.) genotypes contrasting in chilling tolerance. J Plant Physiol. 2007;164:157167.

54. Gupta AK, Kaur N. Seed priming increases crop yield possibly by modulating enzymes of sucrose metabolism in chickpea. J Agron Crop Sci. 2005;191:81-87.

55. Rosa M, Prado C, Podaza G, Internadato $R$, Gonzalez JA, Hilal M, Prado FE. Soluble sugars: Metabolism, sensing and abiotic stress. Plant Signal Behav. 2009;4: 388-393.

56. Karim $\mathrm{S}$, Aronsson $\mathrm{H}$, Ericson $\mathrm{H}$, Pirhonen M, Leyman B, Welin B, Mantyla E, Palva ET, Van Dijck P, Holmstrom KO. Improved drought tolerance without undesired side effects in transgenic plants producing trehalose. Plant Mol Biol. 2007;64:371386.

57. Mittler R. Abiotic stress, the field environment and stress combination. Trends Plant Sci. 2006;11(1):16-19.

58. Cruz de Carvalho $\mathrm{MH}$, Contour-Ansel D. Drought stress and reactive oxygen species: Production, scavenging and signaling. Plant Signal Behav. 2008;3:156165.

59. Zhu Z, Liang Z, Han R. Saikosaponin accumulation and antioxidative protection 
in drought-stressed Bupleurum chinense DC plants. Environ Exp Bot. 2009;66:326333.

60. Fazeli F, Ghorbanli M, Niknam V. Effect of drought on biomass, protein content, lipid peroxidation and antioxidant enzymes in two sesame cultivars. Biol Plant. 2007;51: 98-103.

61. Pastori $\mathrm{G}$, Foyer $\mathrm{CH}$, Mullineaux P. Low temperature-induced changes in the distribution of $\mathrm{H}_{2} \mathrm{O}_{2}$ and antioxidants between the bundle sheath and mesophyll cells of maize leaves. J Exp Bot. 2000;51: 107-113.

62. Stevens RG, Creissen GP, Mullineaux PM. Characterization of pea cytosolic glutathione reductase expressed in transgenic tobacco. Planta. 2000;211:537-545.

63. Chew O, Whelan J, Miller AH. Molecular definition of the ascorbate-glutathione cycle in Arabidopsis mitochondria reveals dual targeting of antioxidant defences in plants. J Biol Chem. 2003;278:4686946877.

64. Unyayar A, Mazmancı MA, Ataça $\mathrm{H}$, Erkurt EA, Coral G. A drimaren blue X3LR dye decolorizing enzyme from Funalia trogii: One step isolation and identification. Enzyme Microbial Technol. 2005;36:1016.

65. Deltoro VI, Calatayud A, Gimeno C, Abado $A$, Barreno $E$. Changes in chlorophyll a fuorescence, photosynthetic $\mathrm{CO}_{2}$ assimilation and xanthophyll cycle interconversions during dehydration in desiccation-tolerant and intolerant liverworts. Planta. 1998;207: 224-228.

66. Czytko HH, Grabowski J, Sandorf I, Weckermann K, Weiler EW. Tocopherol content and activities of tyrosine aminotransferase and cystine lyase in Arabidopsis under stress conditions. J Plant Physiol. 2005;162:767-770.

67. Massacci A, Nabiev SM, Pietrosanti L, Nematov SK, Chernikova TN, Thor K, Leipner J. Response of the photosynthetic apparatus of cotton (Gossypium hirsutum) to the onset of drought stress under field conditions studied by gas-exchange analysis and chlorophyll fluorescence imaging. Plant Physiol Biochem. 2008;46: 189-195.

68. Shao HB, Chu LY, Wu G, Zhang JH, Lu $\mathrm{ZH}, \mathrm{Hu}$ YC. Changes of some antioxidative physiological indices under soil water deficits among 10 wheat (Triticum aestivum L.) genotypes at tillering stage.
Colloids Surfaces B: Biointerfaces. 2007; 54:143-149.

69. Kim YH, Kim CY, Song WK, Park DS, Kwon SY, Lee HS, Bang JW, Kwak SS. Overexpression of sweet potato swpa4 peroxidase results in increased hydrogen peroxide production and enhances stress tolerance in tobacco. Planta. 2008;227: 867-881.

70. Ahmad P, Jaleel CA, Salem MA, Nabi G, Sharma S. Roles of enzymatic and nonenzymatic antioxidants in plants during abiotic stress. Crit Rev Biotech. 2010;30: 161-175.

71. Kusaka $\mathrm{M}$, Ohta $\mathrm{M}$, Fujimura $\mathrm{T}$. Contribution of inorganic components to osmotic adjustment and leaf folding for drought tolerance in pearl millet. Physiol Plant. 2005;125:474-489.

72. Romero-Puertas MC, Corpas FJ, Sandalio LM, Leterrier M, Rodriguez-Serrano $M$, del Rio LA, Palma JM. Glutathione reductase from pea leaves: Response to abiotic stress and characterization of the peroxisomal isozyme. New Phytol. 2006;170: 43-52.

73. Chalapathi Rao ASV, Reddy AR. Glutathione reductase: $A$ putative redox regulatory system in plant cells. In: Khan N A, Singh S, Umar S (Eds.). Sulfur Assimilation and Abiotic Stresses in Plants. Springer. 2008;111-147.

74. Reddy AR, Raghavendra AS, Rao Madhava KV, Raghavendra AS, Reddy KJ. Photooxidative stress. In: Physiology and molecular biology of stress tolerance in plants. Springer- The Netherlands. 2006; 157-186.

75. Ding S, Lu Q, Zhang Y, Yang Z, Wen X, Zhang L, Lu C. Enhanced sensitivity to oxidative stress in transgenic tobacco plants with decreased glutathione reductase activity leads to a decrease in ascorbate pool and ascorbate redox state. Plant Mol Biol. 2009;69:577-592.

76. Hossain MA, Mostofa MG, Fujita M. Cross protection by cold-shock to salinity and drought stress-induced oxidative stress in mustard (Brassica campestris L.) seedlings. Mol Plant Breed. 2013;4:50-70.

77. Hossain MA, Mostofa MG, David J, Burritt, Fujita M. Modulation of reactive oxygen species and methylglyoxal detoxification systems by exogenous glycinebetaine and proline improves drought tolerance in mustard (Brassica juncea L.). Int J Plant Biol Res. 2014;2(2):1001-1014. 
78. Moustakas M, Sperdouli I, Kouna T, Antonopoulou $\mathrm{Cl}$ and Therios I. Exogenous proline induces soluble sugar accumulation and alleviates drought stress effects on photosystem II functioning of Arabidopsis thaliana leaves. Plant Growth Regul. 2012;65:315-325.
79. Cruz FJR, Castro GLS, J Silva DD, Festucci-Buselli RA, Pinheiro HA. Exogenous glycine betaine modulates ascorbate peroxidase and catalase activities and prevent lipid peroxidation in mild water stressed Carapa guianensis plants. Photosynthetica. 2013;51:102-108.

(0) 2019 Meena and Kaur; This is an Open Access article distributed under the terms of the Creative Commons Attribution License (http://creativecommons.org/licenses/by/4.0), which permits unrestricted use, distribution, and reproduction in any medium, provided the original work is properly cited.

Peer-review history:

The peer review history for this paper can be accessed here: http://www. sdiarticle3.com/review-history/37934 